\title{
QUEEN'S
UNIVERSITY
BELFAST
}

\section{Pre-treatment of distillery spent wash (vinasse) with vortex based cavitation and its influence on biogas generation}

Nagarajan, S., \& Ranade, V. V. (2020). Pre-treatment of distillery spent wash (vinasse) with vortex based cavitation and its influence on biogas generation. Bioresource Technology Reports, 11, [100480].

https://doi.org/10.1016/j.biteb.2020.100480

\section{Published in:}

Bioresource Technology Reports

\section{Document Version:}

Peer reviewed version

Queen's University Belfast - Research Portal:

Link to publication record in Queen's University Belfast Research Portal

\section{Publisher rights}

Copyright 2020 Elsevier.

This manuscript is distributed under a Creative Commons Attribution-NonCommercial-NoDerivs License

(https://creativecommons.org/licenses/by-nc-nd/4.0/), which permits distribution and reproduction for non-commercial purposes, provided the author and source are cited.

\section{General rights}

Copyright for the publications made accessible via the Queen's University Belfast Research Portal is retained by the author(s) and / or other copyright owners and it is a condition of accessing these publications that users recognise and abide by the legal requirements associated with these rights.

\section{Take down policy}

The Research Portal is Queen's institutional repository that provides access to Queen's research output. Every effort has been made to ensure that content in the Research Portal does not infringe any person's rights, or applicable UK laws. If you discover content in the Research Portal that you believe breaches copyright or violates any law, please contact openaccess@qub.ac.uk. 
Pre-treatment of Distillery Spent Wash (Vinasse) with Vortex Based Cavitation and

\section{2 its Influence on Biogas Generation}

3 Sanjay Nagarajan ${ }^{\mathrm{a}}$ and Vivek Vinayak Ranade $\mathrm{e}^{\mathrm{a}, \mathrm{b}^{*}}$

4 aMultiphase flows, reactors and intensification group, School of Chemistry \& Chemical

5 Engineering, Queen's University Belfast, Belfast - BT9 5AG, United Kingdom.

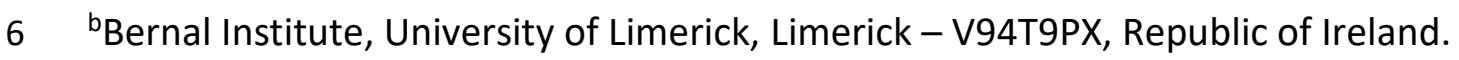

\section{Abstract}

8 Distilleries generate high COD (chemical oxygen demand) wastewater streams that are

9 anaerobically digested to produce biogas with sub-optimal yields. In this work, for the first time, novel vortex-based hydrodynamic cavitation $(\mathrm{HC})$ pre-treatment of these waste streams was investigated for significantly enhancing biogas yields. Molasses spent wash $(120,000$ ppm COD, India) and vinasse (27,000 ppm COD, Brazil) were pretreated at varying number of passes (between $1-20$ ) through the $\mathrm{HC}$ device at constant inflow, biochemical methanation potential (BMP) was measured and described using a first order model. Vortex-based HC pre-treatment led to $14 \%$ enhancement (2 passes) in BMP from spent wash (difficult to digest compared to

17 vinasse) with a net energy gain of $1 \mathrm{GJ} /$ ton COD. 10-22\% increase in biogas yields from large-scale industrial spent wash digesters confirmed the laboratory findings. The work presented is useful and can be translated to recalcitrant feedstock for enhancing valorization using vortex-based HC pre-treatment.

Keywords: hydrodynamic cavitation, spent wash, vinasse, biomethane, energy gain.

\footnotetext{
* corresponding author email: V.Ranade@qub.ac.uk, Vivek.Ranade@ul.ie
} 


\section{Introduction}

Sugarcane industry is one of the largest agri-based industry globally and contributes to $\sim 80 \%$ of world's sugar production. Worldwide sugar prices are falling due to surplus sugar stocks and production (International Sugar Association, 2018). It is therefore inevitable and critical that allied industries such as distilleries that often operate alongside sugar industries support the economic viability. Alcohol fermentation can generate revenue, however, to enhance the profits to support the parent sugar industries, effective waste management and a circular bioeconomy approach is necessary. For instance, a predominant by-product of the sugar industry molasses is utilized by distilleries for alcohol fermentation, where these process generates 10-15 $\mathrm{m}^{3}$ distillery wastewater $/ \mathrm{m}^{3}$ alcohol produced (Christofoletti et al., 2013). With the global ethanol production increasing annually for beverage and fuel purposes the associated wastewater produced is immense [e.g., $>40$ billion liters in India (Basu et al., 2015) and >300 billion liters in Brazil (da Silva Neto et al., 2020)]. Therefore, it is paramount to address the need to manage this wastewater and simultaneously support the sugar industry. Distillery wastewater is known as spent wash, vinasse, slop, stillage or distillery effluent depending upon the source of sugar used for fermentation. If distilleries are solely based on molasses (as in India), typical chemical oxygen demand (COD) of waste water (called as spent wash) ranges between $80,000-160,000 \mathrm{ppm}$ and $\mathrm{pH}$ in the acidic range (Basu et al., 2015). If the distilleries also use sugar cane juice (as in Brazil), typical COD of wastewater (called as vinasse) is much lower (España-Gamboa et al., 2011) and is around $30,000 \mathrm{ppm}$. Variation in the composition and COD is seen due to 
its origin and additionally, presence of trace elements, heavy metals, anionic salts, phenolics and melanoidins are responsible for the characteristic dark brown color. These wastewater streams therefore require treatment prior to discharge. Most common industrial practices for the disposal of spent wash are fertirrigation, biocomposting, incineration and anaerobic digestion (Cooper et al., 2020; Fito et al., 2019). Fertirrigation is the process of using spent wash as a water source to irrigate croplands. This can effectively reduce the water footprint on the agricultural sector and discharge load of the distillery. However, long term use of spent wash for irrigation was reported to affect the soil quality by altering the alkalinity and biodiversity of the soil (Mohana et al., 2009). Biocomposting offers the use of two waste streams generated by the sugar industry, namely, press mud and spent wash. Biologically treated spent wash is mixed with press mud and then biocomposted to produce fertiliser (Chowdhary et al., 2018). This could add value to the industry by selling the fertiliser or could be recycled to the farmlands associated with the industry. In either case, the concerns surrounding the handling of huge volumes of spent wash and required land area to produce the compost in addition to the slow rate of composting limits its use. Incineration is a popular option amongst distilleries, where the spent wash can be burnt to generate heat and electricity as well as recover condensate water for reuse within the facility. Problems associated with the energy cost and maintenance of the incinerators are the main limitations to this technology (Fito et al., 2019). Anaerobic digestion (AD) offers an attractive option, not only for its treatment but also low sludge generation compared to aerobic treatment, low operating costs, robustness to handle varying feed compositions and most importantly 
energy recovery in biogas (Tewari et al., 2007). Biogas generated could then be upgraded to biomethane to meet the requirements of transportation fuel or could be used internally by the sugar industry to satisfy their energy needs and offset the electricity costs. Biomethanated spent wash (digestate from AD) would still not be suitable for discharge as it is not legally permitted in India due to the zero-discharge policy regulating the distilleries (Central Pollution Control Board India, 2015). Further treatment, eg, biological treatments may be necessary to further reduce the COD (Pant \& Adholeya, 2009; Pant \& Adholeya, 2007). In other cases, the digestate can be further composted or in occasional cases directly used as a fertilizer (Tewari et al., 2007).

$A D$, although a suitable technology and the current industrial standard for spent wash valorization, due to its complexity and recalcitrance, its COD conversion rarely exceeds $70 \%$. However, with vinasse, higher conversions are reported mainly due to the higher bioavailability of COD (predominantly present as soluble COD) for digestion. To extract more value and maximize the biogas generation from spent wash by making the available COD more digestible, pre-treatment may be required. A wide range of pre-treatments, from physical, chemical, physico-chemical to biological pretreatments are reported in literature for the spent wash and vinasse as shown in Table S1 in supplementary information. However, these pre-treatment methods are often expensive or energy intensive and may not be suitable at an industrial scale (typically with spent wash flow rates of $20 \mathrm{~m}^{3} / \mathrm{h}$ and above). Scalability and net energy gains of wastewater pre-treatment are reported scarcely in literature. With most available publications it could be seen that a net positive energy gain could not be obtained with many reported pre-treatment 
methods (Chang et al., 1994) (Alkan-Ozkaynak \& Karthikeyan, 2011) (Martín et al., 2002) (Siles et al., 2011) (Schaefer \& Sung, 2008) (Wu-Haan et al., 2010) (EspañaGamboa et al., 2017) (Jiménez et al., 2006) (Mallick et al., 2010). It is therefore essential to develop a scalable pre-treatment method which leads to net energy gains at industrial scales. In this work, the use of a novel vortex based hydrodynamic cavitation $(\mathrm{HC})$ was investigated for the pre-treatment of high COD containing spent wash and vinasse to enhance their biogas generation with a net positive energy gain. (Hydrodynamic) Cavitation is the phenomenon of formation of vaporous microbubbles or cavities in a flowing liquid experiencing local low pressures, its growth and collapse. These collapsing cavities generate localized hot spots with very high temperatures and pressures in addition to intense shear (Saharan et al., 2014). Consequently, highly reactive oxygen species namely hydroxyl radicals $(\mathrm{OH})$ are formed. Hot spots, highly oxidizing radicals and shear generated by HC devices have been utilized for the physico-chemical pre-treatment of lignocellulosic biomass (but never for spent wash or vinasse) for enhancing the biomethane production via AD with a net positive energy gain. These include pre-treatment of agricultural residues (Garuti et al., 2018; Zieliński et al., 2019), grass silage and sugarcane bagasse (Nagarajan \& Ranade, 2019), wheat straw (Patil et al., 2016) and waste activated sludge (Petkovšek et al., 2015) to name a few. Furthermore, HC has also been used to improve the aerobic biodegradability of biomethanated distillery wastewater (Padoley et al., 2012). Most commonly reported HC devices (typically for wastewater treatment) are linear flow devices such as venturi tubes or orifice plates with different throat geometries or multiple holes respectively. These conventional cavitation devices are prone to 
clogging and severe erosion (since cavity collapse occur close to device walls). These problems have been overcome by a vortex based HC device disclosed by Ranade et al (Ranade et al., 2016) where no small holes or constrictions are present and the cavity collapse occurs in the core, away from the walls (Simpson \& Ranade, 2019), thereby improving the life time of the devices.

Vortex based HC devices have been previously employed to successfully treat simulated wastewater (Sarvothaman et al., 2018) and pre-treat lignocellulosic biomasses (sugarcane bagasse and grass silage) to enhance its biochemical methanation potential (BMP) (Nagarajan \& Ranade, 2019). Enhancement in BMP up to $24 \%$ upon 9 passes $\mathrm{HC}$ treatment with a net energy gain of $\sim 2 \mathrm{GJ} /$ ton total solids was promising as a pre-treatment method for spent wash and vinasse.

The aim of this work is to evaluate vortex-based $\mathrm{HC}$ pre-treatment of distillery wastewater streams to significantly enhance its BMP and to quantify potential of net energy gain via pre-treatment. The effect of this pre-treatment on two types of distillery wastewater streams, namely, spent wash originating from sugarcane molasses based distillery (sourced from an industry in India) and vinasse (sourced from Brazil) were investigated. BMP tests of the untreated and $\mathrm{HC}$ treated feedstock were performed. Generated data were analyzed using a first order model following the example of Nagarajan and Ranade (Nagarajan \& Ranade, 2019). The net energy gained due to enhanced BMP obtained using the pre-treatment is discussed. Results from large scale industry tests (from the industry collaborator in India) confirming the lab scale results are also presented. The novelty of this work not only lies in utilizing 
hydrodynamic cavitation for the first time to pre-treat spent wash for enhancing BMP, but also effectively achieving analogous (to laboratory investigations) enhanced biogas generation at an industrial scale. The results will be useful to evaluate and recommend an energy efficient pre-treatment process for spent wash digesters.

\section{Methodology}

\subsection{Materials}

Spent wash (sourced from an Indian sugar mill) was air dried to concentrate it and then the concentrate was dried at $65^{\circ} \mathrm{C}$ to a powder. The spent wash powder was then shipped from India to Belfast. Instead of sending in the slurry, dried spent wash powder was shipped for the ease of transportation. For cavitation experiments, the dry powder of required quantity was mixed with tap water present in the tank of the experimental rig to achieve an initial concentration of $162.6 \mathrm{~g} / \mathrm{L}$ spent wash powder in water. Based on a calibration curve prepared (see supplementary information) this concentration corresponded to a COD of $120,000 \mathrm{ppm}$ which is the typical concentration for spent wash in India. Tap water (also potable) characteristics in Belfast correspond to a total hardness of $125 \mathrm{ppm}$, with a slightly alkaline $\mathrm{pH}$ (Northern Ireland Water, 2020). Nitrates and nitrites as well as heavy metals are present in trace quantities below permissible limits. Therefore, this is not expected to affect the biogas generation. When using real spent wash slurry, the volatiles and residual alcohols present in the liquid will be retained to a greater extent as compared to the dried powder. This may also contribute to the organic fraction utilized towards biogas generation. Vinasse with an initial COD of 27,000 ppm was sourced from a distillery in Brazil and was used as received. Inoculum used for BMP tests were 
obtained from a digester in Agri Food and Biosciences Institute (AFBI), Hillsborough, Northern Ireland, United Kingdom digesting cow slurry and grass silage.

\subsection{Substrate and Inoculum Characterization}

To determine the total solids (TS) present, $1 \mathrm{~g}, 20 \mathrm{~g}$ and $2 \mathrm{~g}$ of spent wash powder, vinasse and inoculum were taken in dry crucibles in triplicates respectively. These were then placed in a Carbolite Gero oven at $105^{\circ} \mathrm{C}$ for $24 \mathrm{~h}$. Upon drying, the crucibles were left to cool down to room temperature and weighed. The weight lost from the sample was attributed to moisture. The crucibles were then transferred to a SNOL 13/1100 LHM01 muffle furnace and held at $550{ }^{\circ} \mathrm{C}$ for $2 \mathrm{~h}$. Upon combusting the samples, the crucibles were allowed to cool down to room temperature and then weighed. The weight lost was recorded as the volatiles solids (VS) content of the sample, whereas the weight of samples left behind in the crucibles were attributed to ash (Franco et al., 2018). COD of spent wash and vinasse were measured by first adding appropriate volumes (as recommended by the kit manufacturer) of the samples to the respective reagent kits with the ranges of $0-15,000 \mathrm{mg} / \mathrm{L} \mathrm{O} \mathrm{O}_{2}$ and $0-1,500 \mathrm{mg} / \mathrm{L}$ $\mathrm{O}_{2}$ respectively purchased from either Hach UK or Merck UK. The mixtures were digested at $148^{\circ} \mathrm{C}$ for $2 \mathrm{~h}$ and upon cooling to room temperature, the digested samples in the vials were measured using a Spectroquant Move 100 spectrometer against digested blanks.

\subsection{HC Pre-treatment}

A HC rig, similar to the one previously reported by Nagarajan and Ranade (Nagarajan \& Ranade, 2019), hosting a vortex based cavitation device with a nominal capacity of $1.2 \mathrm{~m}^{3} / \mathrm{h}$ was used for the cavitation pre-treatment of spent wash and 
vinasse. Details on rig construction and the schematic of the rig can be found in the supplementary information. For a given hydrodynamic cavitation device, the two operating parameters, namely, pressure drop across the device and number of passes through the device are the key performance governing parameters. It has been previously established for the vortex based $\mathrm{HC}$ device that pressure drop across the device does not have a significant impact on device performance (Sarvothaman et al., 2018). Operation with higher pressure drop across the device was therefore preferred because it offers higher flow rate (which reduces potential clogging risks) and higher number of generated cavities. Considering this, in the present work, it was decided to operate the pre-treatment at the maximum discharge pressure of the curve (3.9 bars).

The influence of number of passes through the cavitation device on pre-treatment performance was investigated.

Spent wash pre-treatment was initiated by first filling the rig with tap water to a total volume of $12 \mathrm{~L}$. A required quantity of spent wash powder ( $\sim 1.95 \mathrm{~kg})$ was then added to the holding and allowed to mix with tap water under non-cavitating flow conditions. Dissolution of the required quantity of spent wash powder in water did not lead to any significant increase in the volume of the solution. The solution volume of the spent wash therefore was almost the same as that of tap water taken initially (12 L). In the case of vinasse, $14 \mathrm{~L}$ working volume was used. The volume of the pipe sections, cavitation device and pump used in the experimental set-up was $3.5 \mathrm{~L}$. This volume was initially filled with tap water. For making total working volume of $14 \mathrm{~L}, 11.5$ L of vinasse was added to the holding tank. Under non-cavitating conditions, the contents of the rig flowed through both the bypass and the main lines. An overhead 
stirrer was also placed in the center of the holding tank to facilitate proper mixing and

to ensure no dead zones occurred. Upon mixing under the above-mentioned conditions for 5 minutes, $500 \mathrm{ml}$ sample was withdrawn from the holding tank and named as untreated sample in the spent wash experiments. In case of vinasse experiments, $1 \mathrm{~L}$ sample was taken. Then, the flow through bypass line was completely shut and all flow was diverted through the main line. At this condition, the measured flow rate was $1.54 \mathrm{~m}^{3} / \mathrm{h}$ and the inlet pressure was 3.9 barg. Cavitation inception for the device used, occurs at inlet pressures slightly lower than 1 barg with the extent of cavitation increasing with increase in inlet pressure. With the current configuration, 3.9 barg was the maximum achievable inlet pressure and hence used for all the experiments. Upon setting up the cavitation conditions, $500 \mathrm{ml}$ sample were then taken from the holding tank after 2, 10 and 20 passes for the spent wash experiments. With the vinasse experiments, $1 \mathrm{~L}$ samples were collected from the tank after 1,2 and 5 passes. Withdrawal of samples will reduce working volume of liquid in the system. Previously, for simulated wastewater treatment with the vortex based hydrodynamic cavitation device, it was established that the cavitation performance is independent of the working volume (9-14 L) (Sarvothaman et al., 2018). Only parameter that will be affected by change in volume due to withdrawal of samples is the calculation of number of passes through cavitation device. The number of passes per hour was calculated as flowrate in $\mathrm{m}^{3} / \mathrm{h} /$ volume in $\mathrm{m}^{3}$. The corresponding time required to achieve the reported number of passes were calculated appropriately by considering the change in volume due to sampling. For instance, when ' $X$ ' $L$ was the initial volume for the $\mathrm{HC}$ experiments, and $1 \mathrm{~L}$ was sampled after 1 pass pre-treatment, the time 
required to achieve another 1 pass pre-treatment (net treatment of 2 passes) was based on the working volume of ' $X-1$ ' $L$. Therefore, consistent sampling and time calculations were performed.

The initial temperature of the feed in the holding tank was $~ 18^{\circ} \mathrm{C}$. With the net pumping energy being $25.5 \mathrm{Wh}$, the theoretical maximum temperature increase was found to be $\sim 2{ }^{\circ} \mathrm{C}$. For spent wash, with the number of passes corresponding to a total pre-treatment time of $<9 \mathrm{~min}$ and for vinasse with the time $<3 \mathrm{~min}$. Since the increase in temperature during the pre-treatment experiments was $\sim 2{ }^{\circ} \mathrm{C}$, no efforts were made to control the temperature. All the samples collected were then stored in a refrigerator at $4{ }^{\circ} \mathrm{C}$ prior to $\mathrm{BMP}$ tests.

\subsection{BMP Setup and Kinetics}

Untreated and cavitated spent wash, as well as vinasse were subjected to BMP tests. An automatic methane potential test system, popularly known as AMPTS II and a gas endeavour system (Bioprocess control, Sweden) were used to perform the BMP tests. Since BMP was measured to quantify influence of pre-treatment, indirect means of quantifying this influence by measuring the change in BOD/COD ratio was not undertaken in the present work. The method of setting up a BMP test previously described by Nagarajan and Ranade (Nagarajan \& Ranade, 2019) was used in this case. For each feedstock, 15 reactors were set up that was composed of triplicates of blank tests followed by untreated and cavitated feedstock at various number of passes.

Overhead stirrers were fitted to all the reactors and connected in series. Mixers were operated at $50 \%$ of the maximum speed with a $10 \mathrm{sec}$ on and off cycle. The stirrers mixed the contents of the reactor both in clockwise and counterclockwise directions 
periodically. The reactors were then placed in a water bath that was kept constant at

$41^{\circ} \mathrm{C}$. The gas generated as a result of anaerobic digestion, passed through reactor

outlets to bottles containing $3 \mathrm{M} \mathrm{NaOH}$ and $0.4 \%$ thymolphthalein $\mathrm{pH}$-indicator quantification of the generated biomethane. The obtained results were normalized to standard temperature and pressure (STP, $0{ }^{\circ} \mathrm{C}$ and $\left.1 \mathrm{~atm}\right) . \mathrm{BMP}$ tests were performed for 20 days with vinasse and 29 days with spent wash. BMP of each substrate was calculated using Equation 1 and reported as cumulative biomethane produced.

$$
B M P_{t}=\frac{\left(V_{s, t}-V_{i, t}\right)}{V S_{S}}
$$

where $\mathrm{BMP}_{\mathrm{t}}(\mathrm{ml} \mathrm{CH} / \mathrm{g} \mathrm{VS})$ is the biochemical methanation potential of the substrate at time $t$ (days), $V_{s, t}\left(\mathrm{ml} \mathrm{CH}_{4}\right)$ is the volume of biomethane produced by the substrate at time $t, V_{i, t}\left(\mathrm{ml} \mathrm{CH}_{4}\right)$ is the volume of biomethane produced by the inoculum at time $t$, from the blank tests and $\mathrm{VS}_{\mathrm{s}}(\mathrm{g} \mathrm{VS})$ is the amount of volatile solids present in the substrate fed to the reactor. Triplicates within the sample were used for BMP tests and hence the average of the replicates was used to produce the plots which are reported here. The standard deviation between the replicates for each time point from its mean was calculated and plotted as error bars of the experimental data. Otherwise, generally, potential errors can occur due to differences in the composition of inoculum in each reactor, the degassing time of the inoculum before inoculation, the solids content of the inoculum, use of different batches of inoculum or substrate and sampling from an unmixed holding tank. 

shown in Equation 3.

$277 G=G_{\max 1}\left[1-e^{-k 1\left(t-t_{0}\right)}\right]$ for $t \leq t_{\text {cross }}$

$G=G_{\max 1}\left[1-e^{-k 1\left(t-t_{0}\right)}\right]+G_{\max 2}\left[1-e^{-k 2\left(t-t_{0}-t_{\text {cross }}\right)}\right]$ for $t>t_{\text {cross }}$

where $G_{\max 1}$ and $G_{\max 2}$ are the maximum biomethane that could be generated from the unambiguously, a line was fitted through the first four data points post lag time. The slope and intercept of the linear fit of the first four data points were used to obtain the

value of $t_{0}$. The five model parameters namely, $G_{\max 1}, G_{\max 2}, k 1, k 2$ and $t_{\text {cross }}$ were

obtained using non-linear regression (using the solver tool included in Microsoft Excel).

Unlike untreated spent wash, the BMP data obtained for $\mathrm{HC}$ treated spent wash as well as untreated and $\mathrm{HC}$ pre-treated vinasse did not exhibit diauxic digestion.

Therefore, for all the BMP data except untreated spent wash, a simple first order model shown in Equation 2 was used to process the BMP data (by setting $t_{\text {cross }}$ to a value higher than the period of BMP tests).

\subsection{Statistical Analysis}

Confidence intervals (95\%) of the fitted parameters were obtained using the curve fitting tool in MATLAB. The average confidence intervals for parameter $\mathrm{G}_{\max }$ 
confidence intervals for parameter $k$ were found to be $\pm 10 \%$ and $\pm 21 \%$ for spent wash and vinasse respectively. The error bars shown on all the plots are the standard deviation values calculated from triplicates. The correlation coefficient $\left(R^{2}\right)$ for all the fits were greater than 0.99 . These parameters obtained by processing experimental BMP data are reported and discussed in the Section 3.1.

\section{Results and Discussion}

\subsection{BMP measurement and Kinetics}

The total inlet COD of spent wash and vinasse used for the BMP tests were 120,000 ppm and 27,000 ppm respectively. The measured VS content of these feedstocks were used to establish the relationship between VS and COD. $1 \mathrm{~g}$ COD was acids (España-Gamboa et al., 2011; Wilkie et al., 2000). The maximum biomethane

317 yield in this phase for vinasse was almost twice as that of spent wash, indicating a 
decreased to $\sim 4$ days upon $\mathrm{HC}$ pre-treatment. With vinasse samples, the untreated and 1 pass samples had an initial lag time of $\sim 7$ days, and the rest had a lag time of $\sim 8$ days.

323 Lag phase seen in both the cases could have been due to the use of a non-acclimatized inoculum. An acclimatization stage might have helped to overcome or shorten the lag phase observed with the digestion of spent wash and vinasse.

untreated spent wash in the present work is shown in Figure 1. It can be seen that the

BMP data clearly exhibits three distinct regions. The first day produced significant

biomethane which was subsequently decreased. This initial gas production stage was

also found for both the untreated and pre-treated spent wash as well as vinasse. This

initial gas production phase occurred because of the presence of easily utilizable

fractions such as alcohols, fatty acids or soluble sugars in the feedstock. Once the easily digestible organics were utilized, the net biomethane generation stopped before starting again with the breakdown of complex organics. Since the interest is in understanding digestion of complex COD contained in the feedstocks, the initial data obtained during this phase (called as lag phase here) was not considered for processing the BMP data. Instead, the data was processed by shifting the time coordinate by $t_{0}$, lag time (days).

The BMP data of untreated spent wash shows diauxic digestion (digestion in multiple stages) after the lag phase. This could have been due to the presence of recalcitrant organics in untreated spent wash. Presence of these complex organics affect the overall rate of digestion as well as the cumulative biomethane generation. 
344 (Walter et al., 2016), food waste (Ashekuzzaman \& Poulsen, 2011) and activated

345 sludge (Roebuck et al., 2019) have been reported in the past. With such diauxic digestion, a simple first order model is not appropriate and hence the linear combination of two first order models shown in Equation 3 was used to describe the BMP data obtained with untreated spent wash. Upon pre-treatment, no diauxic gas production was observed with all the other spent wash samples or any of the vinasse samples and hence a simple first order model represented in Equation 2 was used. The fitted model parameters for untreated and $\mathrm{HC}$ pre-treated spent wash samples are shown in Table 1. As seen, $\mathrm{HC}$ pre-treatment has facilitated in lowering the lag time as compared to the untreated sample. Furthermore, a $14 \%$ increase in $\mathrm{G}_{\max }$ was observed upon $\mathrm{HC}$ treatment after just 2 passes. $\mathrm{G}_{\max }$ of 10 passes $\mathrm{HC}$ treated spent wash was found to be similar to that of the 2 passes sample, however in the case of 20 passes $\mathrm{HC}$ treated spent wash, a lower $\mathrm{G}_{\max }$ compared to 2 passes was observed. Additionally, no diauxic gas production was observed with any of the $\mathrm{HC}$ treated spent wash samples indicating that the recalcitrant organics were broken down due to the physico-chemical effect of HC thereby making the COD more digestible (or enhanced soluble COD). Similar effect of cavitation (ultrasonication) on the number of stages in BMP of activated sludge were reported by (Roebuck et al., 2019). Compared to spent wash, a longer lag time was observed with the vinasse samples, but no diauxic gas production was observed, suggesting that the organics were already in its bioavailable form, i.e. as soluble COD. Therefore, a simple first order model (Equation 2) was used to process the BMP data. The data for untreated vinasse showed much larger error bars around day 10. Couple of data points in that 
region were therefore not considered while fitting the Equation 2 . The fitted results are shown in Figure 2(b) and the corresponding model parameters are listed in Table 2. Unlike spent wash, no significant influence of HC pre-treatment on BMP was observed for vinasse. Comparing the observed $\mathrm{G}_{\max }$ with the theoretical value of $\mathrm{BMP}$, one can

371 calculate the COD used (or COD conversion) for biogas generation. It can be seen that HC pre-treatment enhanced COD conversion from 59\% (for untreated spent wash) to $65-68 \%$ (for the HC treated spent wash). With the case of vinasse, the COD conversion ranged between $78-95 \%$ suggesting the presence of easily digestible COD. Low COD removal rates could be primarily due to the use of non-acclimatized inoculum for digestion and possibly also due to no use of nutrients or trace elements to support microbial activity, unadjusted $\mathrm{pH}$ prior digestion, and seasonal variability of feedstock. The inoculum used in our study was obtained from a digester operating on cattle slurry and grass silage as feedstock and was not adapted to digest spent wash. Hence, a lag phase was clearly seen, where only the easily available organics were utilized first (both in the cases of vinasse and spent wash) followed by the recalcitrant organics. $\mathrm{HC}$ pre-treatment helped in breaking down the recalcitrant compounds to an extent thereby also leading to a lower lag time, lack of diauxic digestion from pretreated samples and higher rates compared to untreated samples. An acclimatization phase prior to BMP tests might have possibly resulted in higher COD removal. Bories et inocula to determine its effect on biomethane production (Bories et al., 1988) and reported the need for inoculum acclimatization. Another additional important factor to consider is the inherent variability within the feedstock itself. The effect of seasonal 
and compositional differences of vinasse on BMP has been reported earlier where significantly different values of BMPs was observed for vinasse samples containing similar COD (Janke et al., 2015; Leite et al., 2015). It is evident from these reports that even with a narrow range of COD across samples, differences in the underlying composition of the vinasses may lead to significantly different BMP values. Spent wash and vinasse are known to possess melanoidins which are recalcitrant sugar-amine complexes that are resistant to microbial degradation (Chandra et al., 2008). These refractory complex organic polymers possess a surface charge and interact with metal ions in the active centers of enzymes leading to protein precipitation, thereby making them inactive and unavailable for biomass breakdown. In addition, melanoidins are known antioxidants that can be bactericidal. This may have also led to a lower biomethane yield from the untreated samples. In the case of pre-treated samples, melanoidins could have been partially broken down by the action of HC. Depending on its original chain length, composition of the side chain and molecular weight, a variety of intermediates might have formed due to pre-treatment. With optimal pre-treatment, the available COD may become digestible however with over treatment intermediate inhibitors may be produced thereby lowering the overall biomethane yield. An increase in concentration of toxic intermediates as a result of sonication pre-treatment causing an inhibition to the aerobic biodegradability of distillery spent wash has been reported previously by (Sangave \& Pandit, 2006). In the case of phenolics present in the samples, the type of phenolics present and its solubility in water determines its inhibitory effect. For example, (Hernandez \& Edyvean, 2008) reported an inhibitory concentration of phenolics for biomethane 
413 production (from anaerobic sludge) to be between $800-1,600 \mathrm{mg} \mathrm{C} / \mathrm{L}$. Back of the

414 envelop calculations based on these numbers indicate that an inhibitory effect looks

415 more plausible than the loss of organics due to over treatment. However, further

416 investigations into identification and quantification of inhibitors generated by $\mathrm{HC}$ pre-

417 treatment and their influence on BMP are needed to draw definitive conclusions.

418 Acoustic cavitation studies and its effect on the BMP of stillage was reported by

419 Wu-Haan et al (Wu-Haan et al., 2010). They used a $2.2 \mathrm{~kW} 20 \mathrm{kHz}$ ultrasonic system to

420 pre-treat stillage with an initial COD of $110,000 \mathrm{ppm}$. Combinations of various pre-

421 treatment times ranging from 10-50 s and sonication amplitudes ranging from 33-

$422100 \%$ was used. Batch BMP of the pre-treated and untreated samples were set up and

423 compared under mesophilic conditions. Stillage upon 10 and 20 s sonication at 33\%

424 amplitude showed BMP's lower than the untreated stillage samples, whereas all the

425 other samples showed an increased BMP in comparison. The highest enhancement in

426 BMP of $29 \%$ was observed upon sonication at $66 \%$ amplitude for 10 . Addition of

427 inorganic nutrients and adjusted alkalinity prior digestion could have positively

428 influenced the microbial activity for biomethane generation in Wu-Haan et al's work.

429 In our work however, no trace elements or nutrients were added nor was the alkalinity

430 adjusted. As the inoculum to substrate ratio (on the basis of VS) was 2:1 in our study,

431 the higher quantity of inoculum used was assumed to provide the required buffering

432 capacity. At an industrial scale, addition of trace elements or nutrients are often not

433 favored and hence could support this argument.

$434 \quad 3.2$ Application to large scale digesters 
performed and retrofitted in four distilleries in west and central India with the help of our industry collaborator to pre-treat the incoming spent wash streams for enhanced biomethane generation (Figure 3) (Utikar, 2019). Due to confidentiality, the names of the industries are not disclosed. The average COD loads to these digesters were in the range of $120,000-190,000 \mathrm{ppm}$ and the spent wash inflow rates were in the range of $13-50 \mathrm{~m}^{3} / \mathrm{h}$. The vortex-based $\mathrm{HC}$ device installed upstream of the digester was designed to match the inflow rates thereby achieving one pass $\mathrm{HC}$ treatment before being digested. With just one pass through vortex-based cavitation device, an increase in biogas yield in the range of $10-22 \%$ was observed on these industrial scale digesters. This is for the first time, a fully scaled-up hydrodynamic cavitation-based pre-treatment has been shown to enhance biogas generation by effectively pretreating spent wash at industrial scale. Illustrative energy calculations (gained and required for $\mathrm{HC}$ pre-treatment) were therefore performed for 1 and 2 passes $\mathrm{HC}$ pretreatment for typical industrial spent wash inflow rates of $20 \mathrm{~m}^{3} / \mathrm{h}$ and $50 \mathrm{~m}^{3} / \mathrm{h}$ for 150 days digester operation in a year. These calculations were based on the $\mathrm{G}_{\max }$ enhancement observed upon HC treatment at 2 passes and reported in Table 1. The energy required for pre-treatment; $E_{\text {pre-treatment }}$ can be calculated using Equation 4.

$453 \quad E_{\text {pre-treatment }}=\frac{0.1 \Delta P n_{p}}{C_{f} \eta} \frac{M J}{\text { ton } C O D}$

454 where, $\Delta \mathrm{P}$ is the pressure drop across the vortex-based HC device (bars), $\mathrm{n}_{\mathrm{p}}$ is the number of passes, $C_{f}$ is the concentration of $C O D$ in the feed stream (ton $C O D / \mathrm{m}^{3}$ ) and $\eta$ is the pump efficiency (assumed to be 0.66). The enhanced biomethane generation, 

calculated using Equation 7.

$460 G_{\text {gained }}=\left(\left[G_{\text {max }}\right]_{\text {pre-treated }}-\left[G_{\text {max }}\right]_{\text {untreated }}\right) \frac{m^{3}}{\text { ton } C O D}$

$461 \quad E_{\text {gained }}=\Delta H_{\text {cal }} G_{\text {gained }} \frac{M J}{\text { ton } C O D}$

$462 \quad$ Net Energy Gain $=E_{\text {gained }}-E_{\text {pre-treatment }} \frac{M J}{\text { ton } C O D}$

463

464

where $\Delta H_{\text {cal }}$ is methane's calorific value $\left(M J / \mathrm{m}^{3}\right),\left[G_{\text {max }}\right]_{\text {pre-treated }}$ and $\left[G_{\text {max }}\right]_{\text {untreated }}$ are the $\mathrm{G}_{\max }$ of pre-treated and untreated samples respectively in $\mathrm{m}^{3} \mathrm{CH}_{4} /$ ton COD. At an inflow rate of $20 \mathrm{~m}^{3} / \mathrm{h}$ for a COD load of $120,000 \mathrm{ppm}$, for 1 and 2 passes HC treatment, the corresponding $E_{\text {pre-treatment }}$ were calculated to be $5.8 \mathrm{MJ} /$ ton COD and $11.9 \mathrm{MJ} /$ ton COD respectively and the corresponding net energy gain of $\sim 1 \mathrm{GJ} /$ ton COD at 1 and 2 passes were calculated respectively. In a commercial scenario however, a broad range of COD loads are expected in the feed stream across distilleries all over the country. Hence, for illustrative purposes the influence of HC on net energy gain and $G_{\text {gained }}$ for various COD loads at an inflow rate of $20 \mathrm{~m}^{3} / \mathrm{h}$ was calculated and shown in Figure 4. Similar plot was also prepared for a higher inflow rate of $50 \mathrm{~m}^{3} / \mathrm{h}$ and shown in the supplementary information. It can be seen from Figure 4 that even at a minimum COD load of 0.25 ton COD/h (900 ton COD/year), the net energy gained upon 1 and 2 passes $\mathrm{HC}$ treatment was $0.98 \mathrm{GJ} /$ ton COD and $0.93 \mathrm{GJ} /$ ton COD respectively. Enhanced spent wash BMP upon pre-treatment obtained in the laboratory was also observed with large scale industrial spent wash digesters with a calculated net positive energy gain. This clearly indicates that the novel vortex-based 
480

481

482

483

484

485

486

487

488

489

490

491

492

493

494

495

496

497

498

499

500

501

$\mathrm{HC}$ device can pre-treat spent wash energy efficiently at scale with an enhanced biogas generation. This opens up the possibility to extend its application to other biomass and waste streams that needs pre-treated prior bioprocessing.

\section{Conclusion}

Vortex based HC pre-treatment of spent wash at an inlet pressure of 3.9 barg and 2 passes (initial COD of 120,000 ppm) was found to enhance BMP by $14 \%$. Similar pre-treatment for vinasse (initial COD of $27,000 \mathrm{ppm}$ ) was however insignificant due to its already 'easy to digest' COD. Net energy gains due to the increased biomethane produced from HC treated spent wash was $\sim 1 \mathrm{GJ} /$ ton COD. Scaled-up applications of single pass $\mathrm{HC}$ pre-treatment on industrial spent wash digesters was found to enhance biogas generation (10-22\%) with a range of inlet COD loads $(120,000-190,000 \mathrm{ppm})$.

\section{Supplementary Information}

E-supplementary data of this work can be found in online version of the paper.

\section{Acknowledgements}

This work was supported by Innovate UK, Newton Fund, BBSRC UK and

Department of Biotechnology, Government of India (vWa Project, Grant

BB/S011951/1). Authors would like to gratefully acknowledge our vWa project

partners Dhampur sugar mills for providing the spent wash samples and VIVIRA

Process Technologies for providing data from four large scale digesters. Authors would also like to acknowledge Dr. Chris Johnston and Dr. Gary Lyons of AFBI for sharing their 
502

503

504

505

506

507

508

509

510

511

512

513

514

515

516

517

518

519

520

521

522

523

BMP measurement (AMPTS II) facilities and Mr. Michael Wills of AFBI for his support in operating the AMPTS II.

\section{Declaration of Interest}

One of the authors (VVR) is a co-founder and Director of Vivira Process Technologies Pvt Ltd, India, which commercially offers cavitation devices used in this study.

\section{8}

\section{References}

1. Alkan-Ozkaynak, A., Karthikeyan, K.G., 2011. Anaerobic digestion of thin stillage for energy recovery and water reuse in corn-ethanol plants. Bioresour. Technol., 102(21), 98919896.

2. Ashekuzzaman, S.M., Poulsen, T.G., 2011. Optimizing feed composition for improved methane yield during anaerobic digestion of cow manure based waste mixtures. Bioresour. Technol., 102(3), 2213-2218.

3. Basu, S., Mukherjee, S., Kaushik, A., Batra, V.S., Balakrishnan, M., 2015. Integrated treatment of molasses distillery wastewater using microfiltration (MF). J. Environ. Manage., $158,55-60$.

4. Bories, A., Raynal, J., Bazile, F., 1988. Anaerobic digestion of high-strength distillery wastewater (cane molasses stillage) in a fixed-film reactor. Biological Wastes, 23(4), 251-267.

5. Central Pollution Control Board India. 2015. Guidelines on techno-economic feasibility of implementation of zero liquid discharge for water polluting industries. Ministry of Environment, Forests \& Climate Change. New Delhi, India. 
524 6. Chandra, R., Bharagava, R.N., Rai, V., 2008. Melanoidins as major colourant in 525 sugarcane molasses based distillery effluent and its degradation. Bioresour. Technol., 99(11), $526 \quad 4648-4660$.

527 7. Chang, I.S., Choo, K.H., Lee, C.H., Pek, U.H., Koh, U.C., Kim, S.W., Koh, J.H., 1994.

528 Application of ceramic membrane as a pretreatment in anaerobic digestion of alcohol-distillery 529 wastes. J. Membr. Sci., 90(1), 131-139.

530 8. Chowdhary, P., Raj, A., Bharagava, R.N., 2018. Environmental pollution and health 531 hazards from distillery wastewater and treatment approaches to combat the environmental 532 threats: A review. Chemosphere, 194, 229-246.

533 9. Christofoletti, C.A., Escher, J.P., Correia, J.E., Marinho, J.F.U., Fontanetti, C.S., 2013.

534 Sugarcane vinasse: Environmental implications of its use. Waste. Manag., 33(12), 2752-2761.

535 10. Cooper, J., Kavanagh, J., Razmjou, A., Chen, V., Leslie, G., 2020. Treatment and

536 resource recovery options for first and second generation bioethanol spentwash - A review.

537 Chemosphere, 241, 124975.

538 11. da Silva Neto, J.V., Gallo, W.L.R., Nour, E.A.A., 2020. Production and use of biogas from 539 vinasse: Implications for the energy balance and GHG emissions of sugar cane ethanol in the 540 brazilian context. Environ. Prog. Sustain., 39(1), 13226.

541 12. España-Gamboa, E.I., Mijangos Cortes, J., Barahona Perez, L., Dominguez Maldonado,

542 J., Hernández Zarate, G., Alzate Gaviria, L., 2011. Vinasses: characterization and treatments.

543 Waste Manage. Res., 29(12), 1235-1250.

544 13. España-Gamboa, E.I., Vicent, T., Font, X., Dominguez Maldonado, J., Canto Canché, B., 545 Alzate Gaviria, L., 2017. Pretreatment of vinasse from the sugar refinery industry under non546 sterile conditions by Trametes versicolor in a fluidized bed bioreactor and its effect when 547 coupled to an UASB reactor. J. Biol. Eng., 11, 6-6. 
14. Fito, J., Tefera, N., Van Hulle, S.W.H., 2019. Sugarcane biorefineries wastewater:

549

550

551

552

553

554

555

556

557

558

559

560

561

562

563

564

565

566

567

568

569

570 bioremediation technologies for environmental sustainability. Chem. Biol., 6(1), 6 . 15. Franco, R.T., Buffière, P., Bayard, R., 2018. Co-ensiling of cattle manure before biogas production: Effects of fermentation stimulants and inhibitors on biomass and methane preservation. Renew. Energy., 121, 315-323.

16. Garuti, M., Langone, M., Fabbri, C., Piccinini, S., 2018. Monitoring of full-scale hydrodynamic cavitation pretreatment in agricultural biogas plant. Bioresour. Technol., 247, 599-609.

17. Hernandez, J.E., Edyvean, R.G.J., 2008. Inhibition of biogas production and biodegradability by substituted phenolic compounds in anaerobic sludge. J. Hazard. Mater., $160(1), 20-28$.

18. International Sugar Association. 2018. The World sugar economy in 2018.

\section{https://www.isosugar.org/sugarsector/sugar.}

19. Janke, L., Leite, A., Nikolausz, M., Schmidt, T., Liebetrau, J., Nelles, M., Stinner, W., 2015. Biogas Production from Sugarcane Waste: Assessment on Kinetic Challenges for Process Designing. Int. J. Mol. Sci., 16(9), 20685.

20. Jiménez, A.M., Borja, R., Martín, A., Raposo, F., 2006. Kinetic analysis of the anaerobic digestion of untreated vinasses and vinasses previously treated with Penicillium decumbens. J. Environ. Manage., 80(4), 303-310.

21. Leite, A.F., Janke, L., Harms, H., Zang, J.W., Fonseca-Zang, W., Stinner, W., Nikolausz, M., 2015. Assessment of the Variations in Characteristics and Methane Potential of Major Waste Products from the Brazilian Bioethanol Industry along an Operating Season. Energ. Fuels., 29(7), 4022-4029. 
571

572

573

574

575

576

577

578

579

580

581

582

583

584

585

586

587

588

589

590

591

592

593

594

595

22. Mallick, P., Akunna, J.C., Walker, G.M., 2010. Anaerobic digestion of distillery spent wash: Influence of enzymatic pre-treatment of intact yeast cells. Bioresour. Technol., 101(6), 1681-1685.

23. Martín, M.A., Raposo, F., Borja, R., Martín, A., 2002. Kinetic study of the anaerobic digestion of vinasse pretreated with ozone, ozone plus ultraviolet light, and ozone plus ultraviolet light in the presence of titanium dioxide. Process Biochem., 37(7), 699-706.

24. Mohana, S., Acharya, B.K., Madamwar, D., 2009. Distillery spent wash: Treatment technologies and potential applications. J. Hazard. Mater., 163(1), 12-25.

25. Nagarajan, S., Ranade, V.V., 2019. Pretreatment of Lignocellulosic Biomass Using Vortex-Based Devices for Cavitation: Influence on Biomethane Potential. Ind. Eng. Chem. Res., 58(35), 15975-15988.

26. Northern Ireland Water. 2020. Water Quality Results.

https://www.niwater.com/water-quality-results.aspx.

27. Padoley, K.V., Saharan, V.K., Mudliar, S.N., Pandey, R.A., Pandit, A.B., 2012.

Cavitationally induced biodegradability enhancement of a distillery wastewater. J. Hazard. Mater., 219-220, 69-74.

28. Pant, D., Adholeya, A., 2009. Concentration of fungal ligninolytic enzymes by ultrafiltration and their use in distillery effluent decolorization. World J. Microbiol. Biotechnol., 25(10), 1793-1800.

29. Pant, D., Adholeya, A., 2007. Identification, Ligninolytic Enzyme Activity and Decolorization Potential of Two Fungi Isolated from a Distillery Effluent Contaminated Site. Water, Air, Soil Pollut., 183(1), 165-176.

30. Patil, P.N., Gogate, P.R., Csoka, L., Dregelyi-Kiss, A., Horvath, M., 2016. Intensification of biogas production using pretreatment based on hydrodynamic cavitation. Ultrason. Sonochem., 30(Supplement C), 79-86. 
596

597

598

599

600

601

602

603

604

605

606

607

608

609

610

611

612

613

614

615

616

617

618

619

31. Petkovšek, M., Mlakar, M., Levstek, M., Stražar, M., Širok, B., Dular, M., 2015. A novel rotation generator of hydrodynamic cavitation for waste-activated sludge disintegration. Ultrason. Sonochem., 26, 408-414.

32. Ranade, V.V., Kulkarni, A.A., Bhandari, V.M., 2016. Vortex diodes as effluent treatment devices. US9422952B2.

33. Roebuck, P., Kennedy, K., Delatolla, R., 2019. Ultrasonic pretreatment for anaerobic digestion of suspended and attached growth sludges. Water Quality Research Journal, 54(4), 265-277.

34. Saharan, V.K., Pinjari, D.V., Gogate, P.R., Pandit, A.B., 2014. Chapter 3 - Advanced Oxidation Technologies for Wastewater Treatment: An Overview. in: Industrial Wastewater Treatment, Recycling and Reuse, (Eds.) V.V. Ranade, V.M. Bhandari, Butterworth-Heinemann. Oxford, pp. 141-191.

35. Sangave, P.C., Pandit, A.B., 2006. Ultrasound and enzyme assisted biodegradation of distillery wastewater. J. Environ. Manage., 80(1), 36-46.

36. Sarvothaman, V.P., Nagarajan, S., Ranade, V.V., 2018. Treatment of SolventContaminated Water Using Vortex-Based Cavitation: Influence of Operating Pressure Drop, Temperature, Aeration, and Reactor Scale. Industrial \& Engineering Chemistry Research, 57(28), 9292-9304.

37. Schaefer, S.H., Sung, S., 2008. Retooling the Ethanol Industry: Thermophilic Anaerobic Digestion of Thin Stillage for Methane Production and Pollution Prevention. Water. Environ. Res., 80(2), 101-108.

38. Siles, J.A., García-García, I., Martín, A., Martín, M.A., 2011. Integrated ozonation and biomethanization treatments of vinasse derived from ethanol manufacturing. J. Hazard. Mater., 188(1), 247-253. 
620

621

622

623

624

625

626

627

628

629

630

631

632

633

634

635

636

637

638

639

640

641

642

643

39. Simpson, A., Ranade, V.V., 2019. 110th Anniversary: Comparison of Cavitation Devices Based on Linear and Swirling Flows: Hydrodynamic Characteristics. Industrial \& Engineering Chemistry Research, 58(31), 14488-14509.

40. Tewari, P.K., Batra, V.S., Balakrishnan, M., 2007. Water management initiatives in sugarcane molasses based distilleries in India. Resour. Conserv. Recycl., 52(2), 351-367. 41. Utikar, R.P., 2019. Private communication on behalf of Vivira Process Technologies Pvt Ltd, Pune, India.

42. Walter, A., Silberberger, S., Juárez, M.F.n.-D., Insam, H., Franke-Whittle, I., 2016. Biomethane potential of industrial paper wastes and investigation of the methanogenic communities involved. Biotechnol. Biofuels., 9(1), 21.

43. Wilkie, A.C., Riedesel, K.J., Owens, J.M., 2000. Stillage characterization and anaerobic treatment of ethanol stillage from conventional and cellulosic feedstocks. Biomass. Bioenerg., 19(2), 63-102.

44. Wu-Haan, W., Burns, R.T., Moody, L.B., Hearn, C.J., Grewell, D., 2010. Effect of ultrasonic pretreatment on methane production potential from corn ethanol coproducts. T. ASABE, 53(3), 883-890.

45. Zieliński, M., Rusanowska, P., Krzywik, A., Dudek, M., Nowicka, A., Dębowski, M., 2019. Application of Hydrodynamic Cavitation for Improving Methane Fermentation of Sida hermaphrodita Silage. Energies, 12(3), 525. 
645 Figure 1: Experimental biomethane generation and fitted data from untreated spent

646 wash showing lag phase.

647 Figure 2: Influence of number of passes in HC on BMP of (a) spent wash and (b)

648 vinasse. Symbols denote experimental data and lines denote fitted data.

649 Figure 3: Enhancement in biogas yields from large scale spent wash digesters upon 1

650 pass vortex-based HC pre-treatment (Utikar, 2019).

651 Figure 4: $E_{\text {pre-treatment }}$ (continuous and dashed lines) and $E_{\text {gained }}$ (dotted line) as a result of

$652 \mathrm{HC}$ pre-treatment of spent wash at 1 and 2 passes at an inflow rate of $20 \mathrm{~m}^{3} / \mathrm{h}$.

653

654

655

656

657

658

659

660

661

662

663

664 


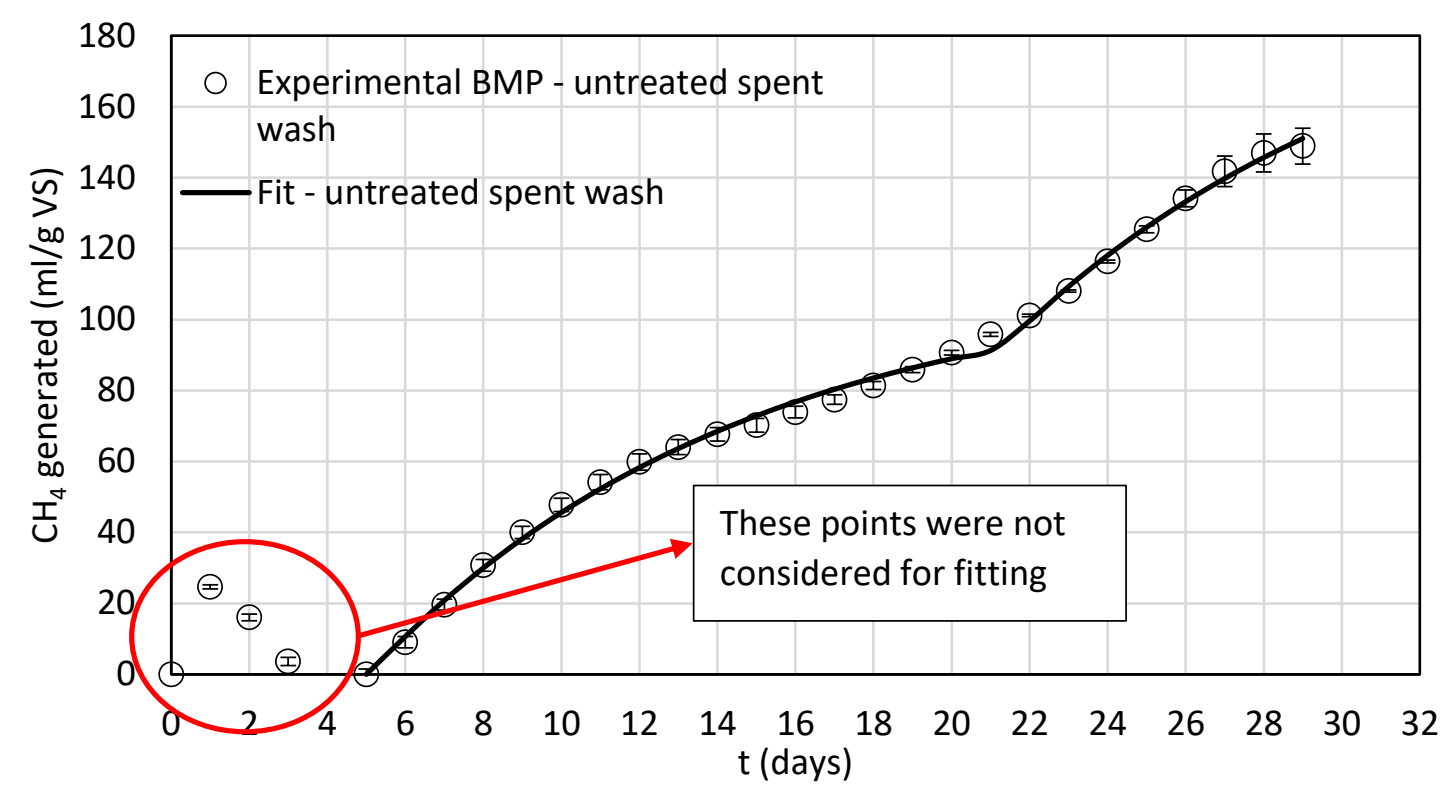

665

Figure 1: Experimental biomethane generation and fitted data from untreated spent

667 wash showing lag phase.

668

669

670

671

672

673

674

675 


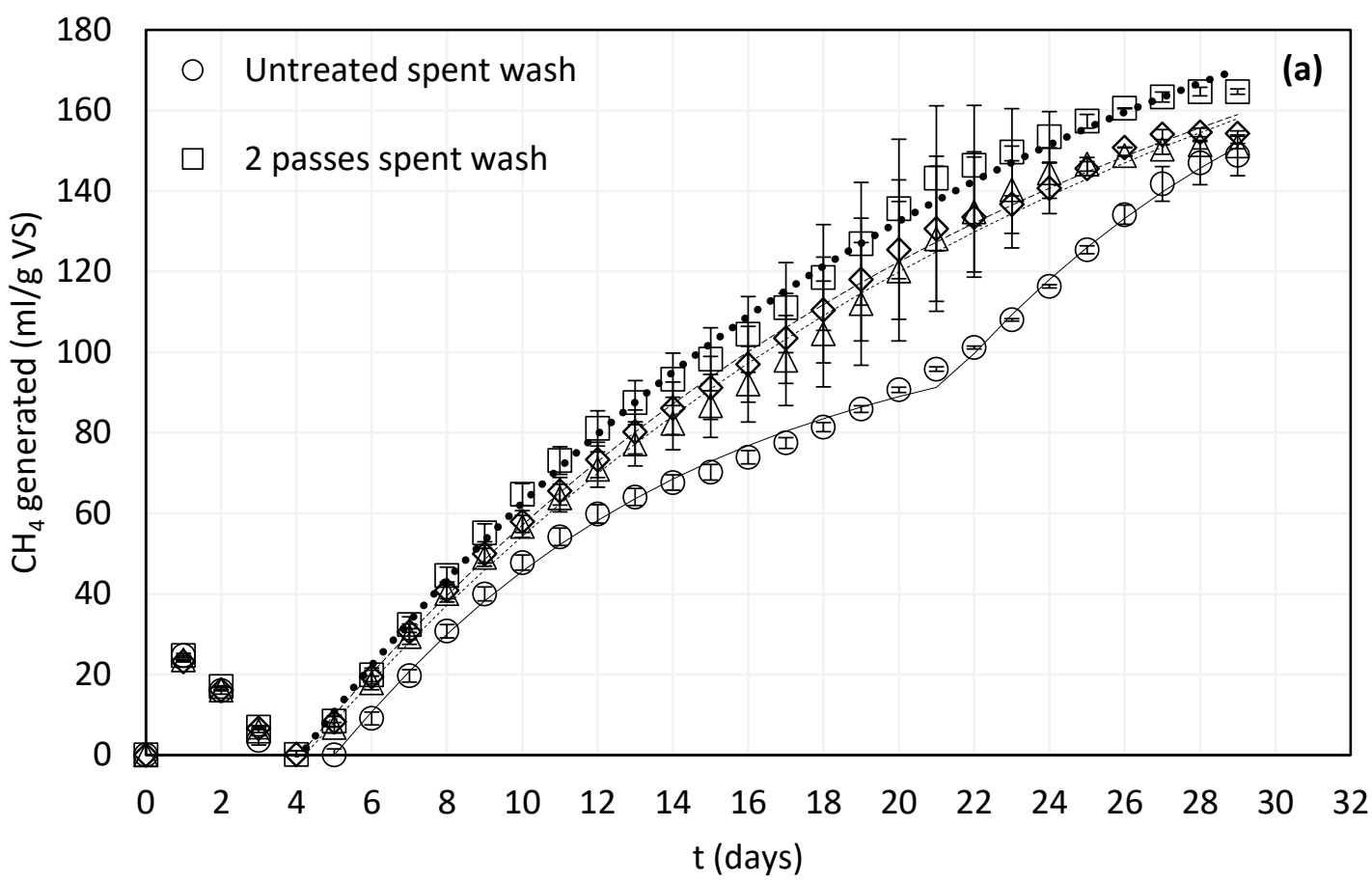

676

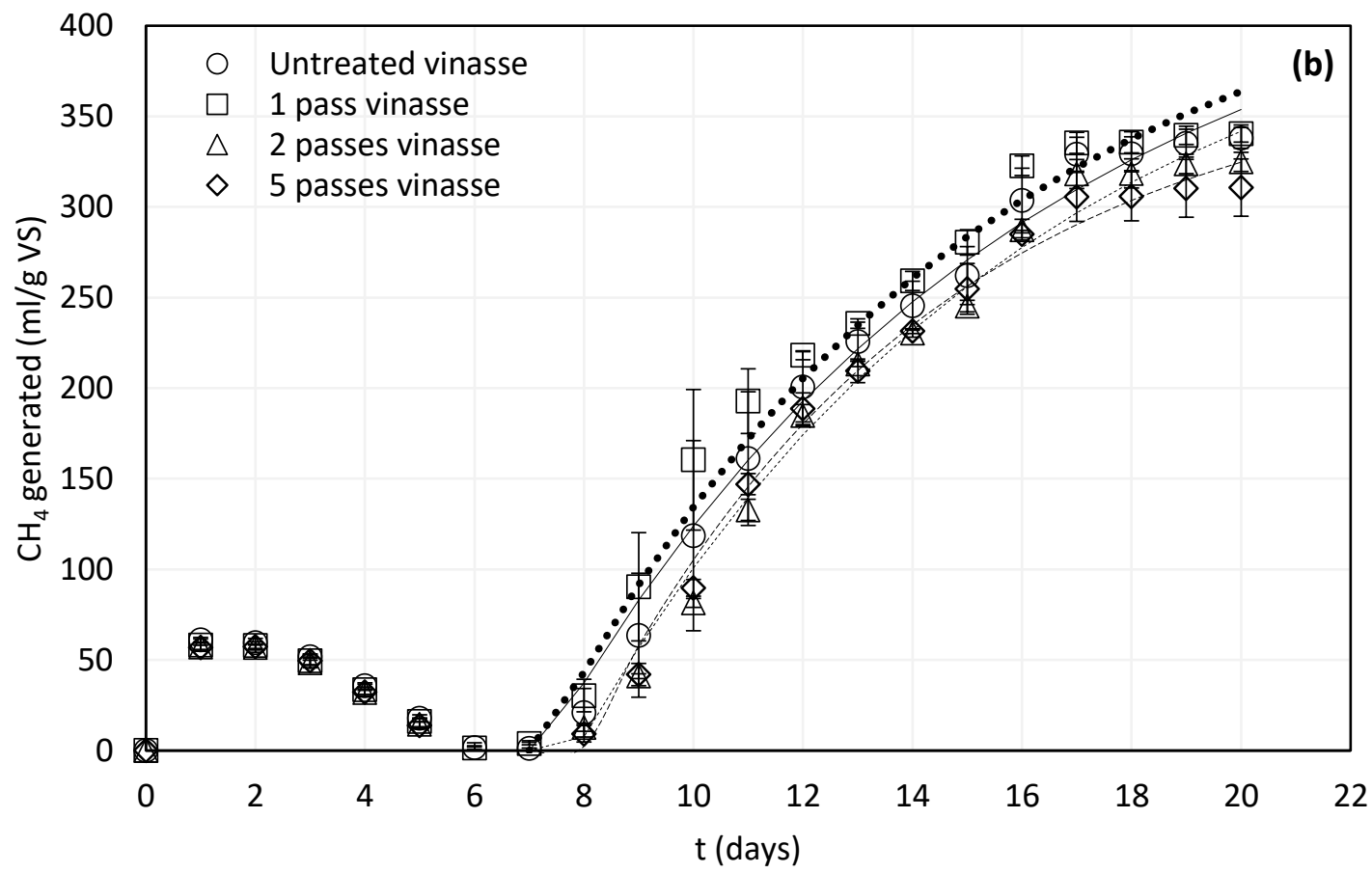

677

678 Figure 2: Influence of number of passes in HC on BMP of (a) spent wash and (b)

679 vinasse. Symbols denote experimental data and lines denote fitted data. 


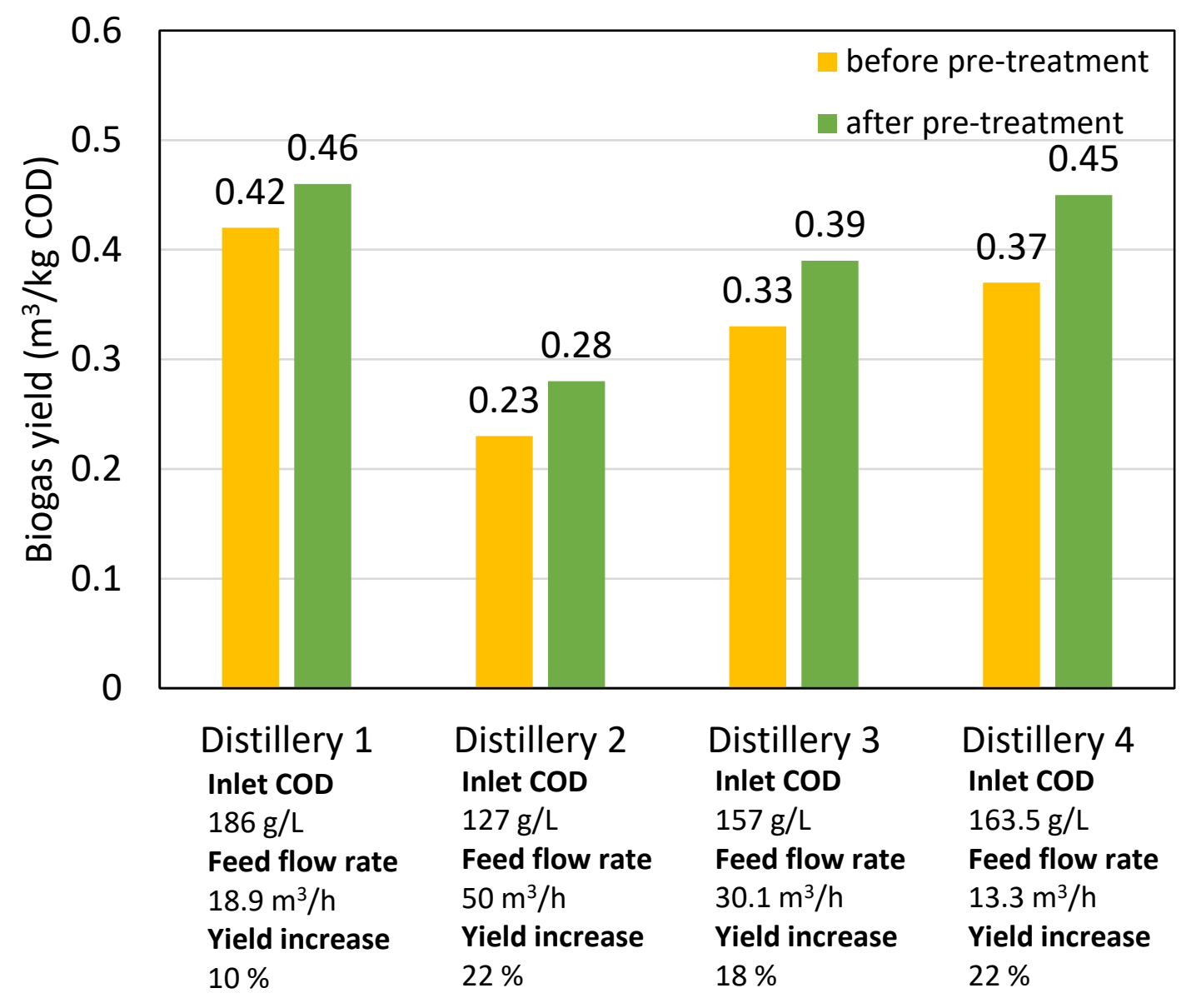

680

681 Figure 3: Enhancement in biogas yields from large scale spent wash digesters upon 1

682 pass vortex-based HC pre-treatment (Utikar, 2019).

683

684

685

686

687

688

689

690

691

692 


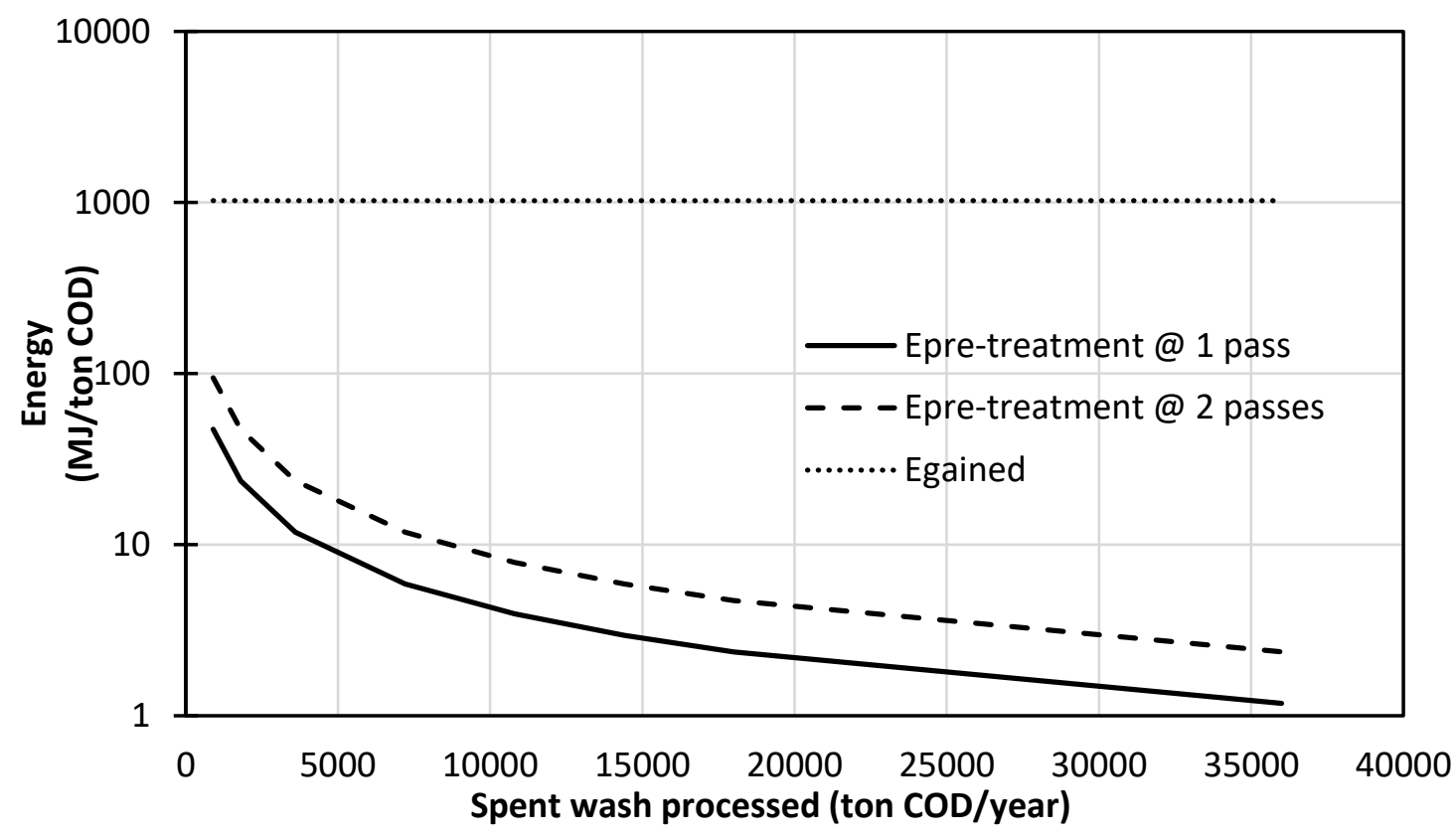

693

694 Figure 4: $E_{\text {pre-treatment }}$ (continuous and dashed lines) and $E_{\text {gained }}$ (dotted line) as a result 695 of $\mathrm{HC}$ pre-treatment of spent wash at 1 and 2 passes at an inflow rate of $20 \mathrm{~m}^{3} / \mathrm{h}$.

696

697

698

699

700

701

702

703

704

705

706 

wash shown in Figure 2(a). ${ }^{*}$ denotes $\mathrm{k} 1$ and ${ }^{\$}$ denotes $\mathrm{k} 2$ observed in untreated spent wash. $95 \%$ confidence intervals for $G_{\max }$ and $k$ are $\pm 7 \%$ and $\pm 10 \%$ of the respective

710 fitted values.

\begin{tabular}{|l|l|l|l|l|}
\hline Parameters & $\begin{array}{l}\text { Untreated spent } \\
\text { wash }\end{array}$ & $\begin{array}{l}\text { Spent wash } \\
-\mathbf{2} \text { passes }\end{array}$ & $\begin{array}{l}\text { Spent wash } \\
-\mathbf{1 0} \text { passes }\end{array}$ & $\begin{array}{l}\text { Spent wash } \\
-\mathbf{2 0} \text { passes }\end{array}$ \\
\hline $\mathbf{G}_{\max }\left(\mathbf{m l ~ C H}_{4} / \mathbf{g}\right.$ COD) & 207 & 236 & 237 & 228 \\
\hline $\mathbf{k}$ (day $^{-1}$ ) & $0.106^{*}$ and $0.097^{\$}$ & 0.054 & 0.046 & 0.050 \\
\hline $\mathbf{t}_{\mathbf{0}}$ (days) & 5.1 & 4.1 & 4.2 & 4.1 \\
\hline
\end{tabular}

711

712

713

714

715

716

717

718

719

720

721

722

723 
724 Table 2: Fitted parameters used in the model to describe the BMP profiles of vinasse

725 shown in Figure 2(b). $95 \%$ confidence intervals for $G_{\max }$ and $k$ are $\pm 12 \%$ and $\pm 21 \%$ of

726 the respective fitted values.

\begin{tabular}{|l|l|l|l|l|}
\hline Parameters & $\begin{array}{l}\text { Untreated } \\
\text { vinasse }\end{array}$ & $\begin{array}{l}\text { Vinasse - 1 } \\
\text { pass }\end{array}$ & $\begin{array}{l}\text { Vinasse - 2 } \\
\text { passes }\end{array}$ & $\begin{array}{l}\text { Vinasse - 5 } \\
\text { passes }\end{array}$ \\
\hline $\mathbf{G}_{\max }\left(\mathbf{m l ~ C H}_{4} / \mathbf{g}\right.$ COD) & 333 & 329 & 322 & 275 \\
\hline $\mathbf{k}\left(\right.$ day $\left.^{-1}\right)$ & 0.114 & 0.124 & 0.119 & 0.158 \\
\hline $\mathbf{t}_{\mathbf{0}}$ (days) & 7.3 & 7.2 & 7.9 & 8.0 \\
\hline
\end{tabular}

727

728

729

730

731

732

733

734

735

736

737

738

739

740

741

742 